NOTES, NEWS \& COMMENTS

\title{
The Foundation for Environmental Conservation: President's Report for the Year 1991*
}

I $\mathrm{n}$ these times of bigness and complexity it often seems that small and relatively simple concerns can still be effective and even widely influential, and so we strive to make our tiny Foundation - despite its minimal budget and dependence almost entirely on our own personal activity with, however, very good encouragement and part-time help. Its main activities during the year under review have been in two categories as follow:

\section{Perennial Projects' Progress}

1) Environmental Conservation:- Once again it has seemed to us that we are sent, unsolicited, from all parts of the world, a gratifyingly large proportion of the most pertinent environmental and conservational writings from which to choose the quarterly issues of our Journal that, in this eighteenth year and volume of its publication following our relinquishing of Biological Conservation, have involved 22 items in the Editorial section, 30 'main' Papers, 19 Short Communications \& Reports, 34 Notes, News \& Comments, 18 Reports of Conferences \& Meetings with, in the same section, 17 Notices of Important Prospects, and 22 Book Reviews and 1 Notice, in addition to cover features and the annual list of Other Books etc. Received during 1990. Thus in the volume were published 164 separately-headed items, usually signed and almost universally original, on a vast range of environmental and/or conservational topics with some 140 illustrations and 95 tables despite the cost. There has also been a gratifying increase in the number of requests for reprinting permissions which are normally granted free provided the purpose is worthy but with a counterrequest for some royalty consideration for at all substantial items that are to be in works for widespread sale.

2) International Conferences on Environmental Future:- The fourth of these established events, held in Budapest, Hungary, in 1990, was the last to be organized by the founder of the series, the future of which he has now handed over to his co-editor on the two latest occasions, Professor Sir John Burnett, following the latter's retirement from running a major university successfully for nearly a decade. Owing to the generosity of the host Hungarian Academy of Sciences and ultimately through their Government, there was no serious financial deficit to make up but still extensive editing and proof-correcting of the Proceedings book of more than 600 pages to be done through much of 1991 to end the 20 years' responsibility for the ICEFs, for the continuation of which we understand there are attractive prospects. Meanwhile the much smaller book on the 3rd ICEF has been gratifyingly well received and reviewed.

3) World Council For The Biosphere:- Whereas this was useful in its early stages in helping to warn people widely of the fragility of The Biosphere and consequently of the imperative need to take care of it rather than the more solid Planet Earth, various of the Council's functions have latterly been so widely taken on by numerous bodies practically world-wide that we have come to wonder whether it could not be terminated without serious loss. But when, in its 1991 AGM - held 'par lettre' with the permission of the governmental

* Slightly updated following the Foundation's 17th Annual General Meeting on 27 March 1992. supervisors - the Councillors were sounded about this, enough responded that it should not be ended without at least a further meeting, so this has been provisionally arranged for Saturday, 14th November 1992, at Sonloup près Les Avants sur Montreux, Switzerland, when the relationship of WCB to Biosphere Day (see ' 6 ' below) should also be discussed.

4) Environmental Monographs \& Symposia and Cambridge Studies in Environmental Policy:- Whereas no new book in either series was published quite within the year under consideration, in the former series Professor Andrew S. Goudie's Techniques of Desert Reclamation continued to be very favourably reviewed. In the latter series of smaller 'readers', Professor Lynton K. Caldwell's Between Two Worlds: Science, the Environmental Movement, and Policy Choice, has also been very favourably received, and so more volumes are under contract or consideration, although it has not proved practicable to hold any meeting of the Editorial Board at all recently.

5) World Who's Who in Environment \& Conservation: Leading Specialists, Administrators, and Benefactors:- With the termination, indicated in ' 2 ' above, of personal responsibility for the ICEFs, it has been possible to contemplate in earnest this long-planned project to the compilation and publication of which we are virtually committed. Consequently it was reassuring to have the printed Questionnaire approved in principle at the Foundation's 17th AGM and the Foundation's confidential Awards Committee strengthened in prospect for speedy advance in their major undertaking of choosing those world-wide to whom questionnaires are to be sent for pertinent biographical details for inclusion in this unique compilation. The present hope is to have about 3,000 biographies in sizeable print in a largish volume of some 400-500 pages, with appendices indicating representation of subjects and by country, though to attain any such scale will require considerably more financing than is currently available.

6) Biosphere Day:- As a follow-up of the World Campaign For The Biosphere (1982-) it was "proposed, on 21 September 1991, before a distinguished gathering assembled for the purpose at the headquarters of the Foundation, that the same day on the calendar annually henceforth be solemnly observed and duly celebrated throughout the world as Biosphere Day. The significance of the chosen date is that it presages the Autumnal Equinox of equal division of night and day in the Northern Hemisphere and similarly the Spring Equinox in the Southern Hemisphere, while the objective of the proposal is to remind the world annually of the fragility of our only life-support, with the consequent need to safeguard it looming as our foremost Human imperative.'. Biosphere Day is widely hailed as a worthy corollary to UNEP's Environment Day (5 June), on which is announced the winner or winners of each year's International Sasakawa Environment Prize, and it is recommended as desirable that Biosphere Day be similarly related to the larger new Blue Planet Prize of which the President is a 'nominator'.

7) Best Paper Prize:- This was divided four ways equally between: a) Professor Ian G. Simmons, for his paper entitled 'The Mid-Holocene Ecological History of 
the Moorlands of England and Wales and Its Relevance for Conservation'; b) Dr Olaf Peterson, for his paper entitled 'The History of Lake Hornborga: A Lesson in Wetland Function and Management from Sweden'; c) Dr Robert J.A. Goodland, Dr Emmanuel O.A. Asibey, Jan C. Post \& Mary B. Dyson, for their paper entitled 'Tropical Moist Forest Management: The Urgency of Transition to Sustainability'; and d) Karen Holl, Gretchen Daily \& Professor Paul R. Ehrlich, for their paper entitled 'Integrated Pest Management in Latin America'. Choice of the winners of these yearly awards is purely by the Foundation's confidential Awards Committee, acting as an independent body, but on this occasion our Journal's publishers, Elsevier Sequoia SA, learning of the multiplicity of awards and further complexity of authorship, generously subsidized the Prizes so that a respectable amount went to each of the 9 Authors involved.

\section{Additional Themes Initiated}

8) Human-caused Soil-ecological Changes and Their Effect on The Biosphere:- While this vast project is far beyond the capability of our modest little Foundation to do much about, we, with a leading associate in Russia, who pushed the idea, were originators of the Vernadsky International Centre for Biosphere Studies, now established as a unit of the Russian Academy of Sciences and located in Pushchino near Moscow, which, at its initial meeting in June 1991, adopted the project at the urging of the same leader who told us that it was his last ambition to see it in being. As he died soon thereafter, we feel responsible for pushing what is basically his project, and welcome the Foundation's encouragement to do so in memory of the Russians' 'grand old man of soil science', which of course is their traditional subject.

9) Equable Use of The Biosphere's Commons:- These include the world's oceans and atmosphere, and the need to support this theme and also item ' 10 ' is being stressed in Environmental Conservation, especially in this Spring 1992 issue, with the active intention of continuing to encourage them both henceforth.

10) Environmental Impact Assessment Before Financing:- - See item '9' above and note that a representative of the Foundation (who has had many years of banking experience particularly at the international level) will be going to advocate both in every possible way at the UNCED 'Earth Summit' in Rio de Janeiro in June 1992.

11) World Collating Office of Environmental Education:- This has long seemed to us increasingly desirable in view of the vital importance of environmental education, the growth of national and regional bodies (such as NAEE) but continuing inactivity of ISEE, and the need for concerted action globally whenever appropriate. Accordingly an International Workshop on Environmental Education has been arranged by a Brazilian associate to take place in Rio de Janeiro on 4 and 5 June during UNCED - to enable delegates to describe the current state and foreseeable problems of Environmental Education in their respective countries, to adopt a framework of action at the global level, and, if appropriate, to establish an International Council For Environmental Education.

The extent to which the above four additional themes will prove implementable will emerge in due course, a current thought regarding the fourth being that a small office in the International Academy of The Environment might be most appropriate.

NichOLAS Polunin, President \& Editor
Foundation for Environmental Conservation
7 Chemin Taverney ( 7 th \& 8th Floors)
1218 Grand-Saconnex
Geneva, Switzerland.

Nicholas Polunin, President \& Editor 7 Chemin Taverney (7th \& 8th Floors) Geneva, Switzerland.

\section{Environmental Help for Management}

A new information service, aimed at helping those with new-found environmental responsibilities in their jobs, is being launched by the British Conservation Foundation. The service is a part of the Environmental Managers' Group, which is intended to help the many people who find that their job-specifications now cover environmental issues for which they may have little or no training. Thus it is clear from the enquiries we receive, that there are many companies which are taking the call to become more environmentally-aware and responsible entirely seriously, but the number which can afford a fulltime, environmentally trained manager can only involve a small proportion.

The launch of the Foundation's Environment Managers' Group coincides with the findings of a survey carried out by the British Institute of Management (BIM), which found that $66 \%$ of respondents to their 'Managing the Environment' questionnaire felt that they or their colleagues would benefit from access to information and training materials that had been prepared and produced specifically for environmental managers.

In addition to general information, the Environmental Managers' Group will also offer members free legal advice provided by two firms of lawyers. The Foundation has run a free 'Environment and the Law' service to the general public, backed by the celebrated firm of Lee \& Pembertons, for over a year. Now it is extending the service by also involving Baker \& McKenzie, one of the world's largest law-firms, to add international advice and perspectives. Fifty-two per cent of the BIM respondents said that their greatest need was for general information on current environmental laws or proposals.

The Conservation Foundation hopes that members will provide much of the expertise which will make practicable an exchange of experience of environmental problems and remedies through fact-sheets and workshops. Backing the initiative is the Conservation Foundation's Founding Director, David Bellamy, who commented:

'Although environmental groups ... are doing vital work, it will be up to industry to solve many of the world's problems. Everywhere I go I meet people who have heard the message, but need help to put their concern into actions. I would like to think that, through the Group, every company listed in Yellow Pages can have their questions answered'.

For further information please contact: David Shreeve, Conservation Foundation, Tel. (071) 8238842.

DAVID SHREEVE, Director
The Conservation Foundation
l Kensington Gore
London SW7 $2 A R$
England, UK.
The Conservation Foundation London SW7 $2 A R$ England, UK. 